\title{
PENGEMBANGAN PANDUAN PELAKSANAAN SOSIODRAMA UBRUG UNTUK MENINGKATKAN KOMUNIKASI INTERPERSONAL
}

\author{
Mia Gusmaniar ${ }^{1}$, Rahmawati2 $^{2}$, Arga Satrio Wibowo ${ }^{3}$ \\ Universitas Sultan Ageng Tirtayasa \\ Email :mi.gusmaniar@gmail.com
}

\begin{abstract}
The purpose of this study was to develop a guidebook for the implementation of the Ubrug Banten sociodrama as a group building method in order to improve students' interpersonal communication skills. This research was developed based on aspects of interpersonal communication which includes openness, empathy (empathy), supportiveness, positiveness and equality. The research method uses R\&D. The development model uses ADDIE which is simplified into three stages, namely analysis, design and development. The data collection technique used is by conducting an expert due diligence on the product being developed. Statistical data analysis techniques for product development feasibility tests quantitatively and qualitatively. Based on the validation results, it is known that the assessment of the media expert's assessment of the ubrug sociodrama guidebook product obtained a total score of $85 \%$ with very feasible criteria, while the assessment of material experts on the material contained in the ubrug sociodrama guidebook product obtained a total score of $81 \%$ with criteria very worthy. The Ubrug sociodrama guidebook can assist counseling teachers in delivering material on interpersonal communication skills by means of group guidance with sociodrama techniques in an effort to learn and preserve the cultural arts of the Ubrug Banten area and can assist students in improving interpersonal communication skills through exercises from student journals or assignments found in the guidebook for the Ubrug sociodrama.
\end{abstract}

Kata Kunci : Interpersonal Communication Skills, Sosiodrama Implementation Handbook, Ubrug Banten

\section{PENDAHULUAN}

Masa remaja menjadi masa yang sangat berpengaruh terhadap perkembangan individu karena pada masa remaja, individu mulai banyak bersosialisasi dengan lingkungan, salah satunya di dalam lingkungan sekolah. Siswa sebagai remaja yang penuh dengan perubahan fungsional dan emosional seringkali menjadi lebih tidak terkendali sehingga terkadang pada saat berkomunikasi dengan temannya di sekolah 
yang seharusnya dapat mendekatkan hubungan emosional justru dapat menyebabkan kerenggangan hubungan.

Morreale dan Pearson (De Vito, 2013) menyatakan keterampilan komunikasi interpersonal atau komunikasi antar pribadi sangat penting bagi keberhasilan professional seseorang. Rakhmat (2004) menjelaskan bahwa komunikasi interpersonal yang baik akan menciptakan kebahagiaan, karena komunikasi dapat membentuk rasa pengertian, persahabatan, pemahaman, akan pengetahuan dan dapat melestarikan peradaban. Sehingga komunikasi interpersonal yang baik dapat menciptakan keberhasilan dalam proses adaptasi. Aspek keterampilan komunikasi interpersonal menurut De Vito (2013), yaitu mindfulness (kesadaran) cultural sensitivity (sensitivitas budaya), other orientation (orientasi lainnya), openness (keterbukaan), supportness (dukungan) metacommunacation, immediacy (kedekatan), flexibility (fleksibilitas), expressiveness (ekspresif), emphaty (empati), dan interacation management (manajemen interaksi). Kurangnya rasa empati, sikap terbuka dan aspek aspek lainnya akan menyebabkan siswa yang tidak dapat menjalin hubungan yang baik dengan orang lain dan begitupula sebaliknya.

Penelitian Pranoto dan Mahardayani (2010) mendapatkan hasil dari 180 remaja di Kabupaten Kudus menunjukkan 94\% menyatakan pernah melakukan tindakan yang tidak menyenangkan terhadap orang lain. Tindakan tidak menyenangkan melalui komunikasi yang sering dilakukan adalah mengejek dan memberikan julukan. Sasaran atau kepada siapa tindakan tidak menyenangkan tersebut dilakukan adalah $50 \%$ kepada teman sekelas, $16 \%$ adik kelas, $14 \%$ kepada anak dari sekolah lain, $7 \%$ kepada kakak kelas dan 5\% kepada guru. Data-data tersebut bermakna siswa kurang mampu menunjukkan sikap kesetaraan dan sikap positif kepada teman sebayanya. Pada lingkungan sekolah, komunikasi interpersonal berperan penting untuk menunjang siswa dalam berkomunikasi dengan sesama siswa, guru dan tenaga administrasi selama berada di sekolah (Djannah dan Drajat, 2012). Menyadari bahwa lingkungan sekolah merupakan lingkungan yang lebih luas dari pada lingkungan keluarga, karena lingkungan sekolah terdapat banyak orang yang memiliki latar belakang yang berbeda-beda. Siswa yang memiliki komunikasi interpersonal yang baik akan mudah bersosialisasi dengan lingkungan dimana siswa itu berada. Hubungan interpersonal yang baik tercipta apabila ada komunikasi yang baik. Untuk menumbuhkan komunikasi interpersonal yang baik, diperlukan sikap terbuka, sikap percaya, sikap mendukung yang mendorong timbulnya sikap saling memahami, menghargai dan mengembangkan kualitas. Maka dari itu peran guru bimbingan dan konseling dalam menghadapi masalah tersebut sangatlah penting adanya upaya preventif maupun kuratif dari guru bimbingan konseling.

Berdasarkan hasil studi pendahuluan dengan koordinator BK dan guru pembimbing di SMPN 11 Kota Serang, peneliti memperoleh temuan dimana siswa memiliki kendala ditinjau dari kemampuan komunikasi antar pribadi atau komunikasi interpersonal dinilai kurang optimal yang terjadi diantaranya pada siswa kelas VIII. Berdasarkan hasil wawancara dengan guru bk, diketahui terdapat beberapa orang siswa dengan jumlah sekitar 12 orang dari 40 orang siswa, khususnya siswa yang kurang berprestasi saat di kegiatan konseling dengan guru BK kurang dapat menyampaikan pendapatnya atas permasalahan yang dihadapinya maupun keluh kesahnya dalam kegiatan pembelajaran di kelas sehingga membuat hasil 
belajarnya kurang baik atau tidak mencapai target kriteria ketuntasan minimal (KKM) pada mata pelajaran tertentu maupun pada seluruh mata pelajaran.

Pada dasarnya komunikasi interpersonal seseorang dapat dilatih dan diasah dengan berbagai macam cara, salah satunya dengan cara bermain peran. Dalam kegiatan belajar mengajar di sekolah, bermain peran diajarkan oleh guru mata pelajaran bahasa Indonesia dengan menggunakan metode sosiodrama. Roestiyah (2008) menyatakan dengan metode sosiodrama, siswa dapat mendramatisasikan tingkah laku, atau ungkapan gerak-gerik wajah seseorang dalam sosial antar manusia, atau siswa dapat memainkan peranan dalam dramatisasi masalah sosial atau psikologis. Melalui metode ini para siswa diajak untuk belajar memecahkan dilema-dilema pribadi yang mendukungnya dengan bantuan kelompok social yang anggotaanggotanya adalah teman-teman sendiri. Dengan kata lain, dilihat dari dimensi pribadi, model ini berupaya membantu individu dengan proses kelompok sosial.

Penggunaan teknik sosiodrama dapat menggunakan berbagai jenis dan tema dari pertunjukan bermain peran, salah satunya adalah Ubrug. Ubrug sebagai warisan budaya Banten dapat dipergunakan sebagai tema dalam sosiodrama. Ubrug merupakan media hiburan rakyat, dapat pula menjadi media pembelajaran bahasa dan sastra daerah bagi generasi muda, serta media informasi layanan masyarakat. Sebagai media pembelajaran bahasa dan sastra daerah, guru bahasa Indonesia dan seni dapat meluangkan waktu bersama para siswa menonton pertunjukan ubrug, agar siswa dapat mengenal, memahami, dan mengapresiasi budaya daerahnya sendiri. Bermain sosiodrama Ubrug membutuhkan buku pedoman panduan bagi guru maupun siswa dalam melatih keterampilan komunikasi interpersonal siswa. Buku panduan merupakan salah satu bentuk dari bahan ajar cetak yang sering dijumpai. Berdasarkan arti kata panduan menurut kamus bahasa Indonesia, maka dapat disimpulkan bahwa buku panduan adalah buku yang menyajikan informasi dan memandu atau memberikan tuntunan (acuan) kepada pembaca untuk melakukan apa yang disampaikan di dalam buku tersebut dengan mudah. Buku panduan ini berisi tentang teknik sosiodrama ubrug dan komunikasi interpersonal. Kompetensi yang diharapkan dengan adanya buku panduan ini guru BK mampu melakukan teknik sosiodrama ubrug untuk meningkatkan komunikasi interpersonal siswa dengan baik.

Berdasarkan deskripsi latar belakang sebelumnya dapat diketahui bahwa sosiodrama ubrug dapat digunakan sebagai teknik yang menarik dalam rangka meningkatkan keterampilan komunikasi interpersonal siswa. Maka, rumusan masalah dalam penelitian ini, yaitu "Bagaimanakah Pengembangan Buku Pedoman Pelaksanaan Teknik Sosiodrama Ubrug Untuk Meningkatkan Komunikasi Interpersonal Pada Siswa Kelas VIII ?"

\section{METODE}

Populasi menurut Sugiyono (2017) ialah wilayah generalisasi yang terdiri dari objek/subjek yang mempunyai kualitas dan karakteristik tertentu serta telah ditetapkan oleh peneliti untuk dipelajari dan kemudian ditarik kesimpulannya. Sampel adalah sebagian dari populasi yang telah ditentukan (Sugiyono, 2012). Pada penelitian ini menggunakan teknik pengambilan sampel menggunakan sampling quota. Arikunto (2010) mengartikan teknik 
sampel kuota adalah teknik untuk menentukan sampel dari populasi dengan karakteristik tertentu sampai jumlah (kuota) yang diharapkan. Jumlah sampel yang akan dilibatkan ialah sebanyak 40 siswa kelas VIII SMP Negeri 11 Kota Serang.

Penelitian ini menggunakan metode penelitian dan pengembangan (research and development). Sugiyono (2017:297) menyatakan metode penelitian dan pengembangan adalah metode penelitian yang digunakan untuk menghasilkan produk tertentu, dan menguji keefektifan dari produk yang dihasilkan tersebut. Puslitjaknov (Putra, 2011:133) dalam penelitian pengembangan terdapat model pengembangan sebagai dasar untuk mengembangkan produk yang akan dihasilkan. Model pengembangan dapat berupa model prosedural, model konseptual dan model teoretik. Pada penelitian ini, model prosedural digunakan karena dianggap cocok dengan tujuan penelitian, yakni untuk menghasilkan produk dan menguji kelayakan produk yang dihasilkan berupa buku panduan pelaksanaan sosiodrama ubrug. Pelaksanaan penelitian metode R\&D dalam penelitian ini merujuk pada prosedur yang dikembangkan oleh Branch (2009) menggunakan model pengembagan ADDIE.

Pada penelitian ini instrumen penelitian yang digunakan antara lain: Self Assesment Ketrampilan Komunikasi Interpersonal; Instrumen Validasi Ahli Media; Instrumen Validasi Ahli Materi. Teknik analisis data yang diterapkan dalam penelitian dan pengembangan ini adalah dengan cara mengumpulkan data melalui instrumen pengumpulan data, kemudian dianalisis dengan mengacu pada prosedur penelitian dan pengembangan. Analisis data pada penelitian ini dilakukan secara kuantitatif dan kualitatif.

\section{HASIL DAN PEMBAHASAN}

Penelitian dan pengembangan ini menghasilkan produk buku panduan pelaksanaan sosiodrama Ubrug untuk meningkatkan keterampilan komunikasi interpersonal siswa. Sosiodrama merupakan salah satu teknik yang dapat digunakan dalam bimbingan kelompok melalui dramatisasi tingkah laku individu terhadap individu lainnya dalam hubungannya dengan masalah sosial. Proses bimbingan kelompok yang menggunakan teknik sosiodrama cenderung obyeknya bukan benda atau kegiatan sebenarnya, melainkan kegiatan bimbingan kelompok yang bersifat pura-pura. Di samping itu dalam teknik sosiodrama siswa diajak untuk bermain peran beberapa perilaku yang dianggap sesuai dengan tujuan bimbingan yang ingin dicapai.

Teknik sosiodrama dimaksudkan untuk meminimalisir masalah dan kesulitan dari siswa dalam berkomunikasi dan meningkatkan kepercayaan diri. Pada teknik sosiodrama, peserta didik diharapkan dapat memperoleh dorongan atau kekuatan untuk menjaga hubungan interaksi dengan sesama lawan bicaranya dengan kuat. Teknik sosiodrama dijadikan alat untuk mengatasi peserta didik yang memiliki kemampuan interaksi sosial yang rendah dengan cara bermain peran. Pada teknik sosiodrama, dinamika kelompok yang tercipta lebih dinamis karena setiap peserta didik diberi tugas untuk dapat memainkan peran dapat berusaha mengekplorasi perilakunya sesuai dengan perannya. Hal ini dapat meningkatkan 
kemampuan komunikasi seseorang dan mengeksplorasi perilaku seseorang yang sebelumnya terpendam. Saat bermain peran, siswa yang tadinya adalah siswa yang pemalu, pasif, kurang ekspresif kemudian berubah menjadi siswa yang berani berbicara isi dialog di hadapan teman-temannya di kelas sesuai dengan karakter peran yang dimainkannya, menjadi individu yang aktif saat berada di dalam dan di luar kelompoknya dan menjadi siswa yang ekspresif saat berkomunikasi, seperti menggunakan gerak badan (gesture) hingga penggunaan mimik muka yang ekspresif sebagai simbol penguat dalam suatu kegiatan komunikasi sebagai tahapan awal melatih siswa untuk memperbaiki masalahnya dalam komunikasi interpersonal.

Penggunaan teknik sosiodrama dapat menggunakan berbagai jenis dan tema dari pertunjukan bermain peran, salah satunya adalah Ubrug. Hasil uji kelayakan yang telah dilakukan pada produk penelitian dan pengembangan ini berupa buku panduan pelaksanaan sosiodrama Ubrug untuk meningkatkan keterampilan komunikasi interpersonal siswa menjadi tolak ukur kelayakan pengembangan program bimbingan kelompok. Kesimpulan dari penilaian ahli media dan ahli materi menunjukkan produk buku panduan pelaksanaan sosiodrama Ubrug dalam kategori sangat layak untuk di implementasikan. Tercatat penilaian dari ahli media atas produk buku panduan sosiodrama ubrug memperoleh total skor sebesar 85\% dengan kriteria sangat layak, sedangkan penilaian dari ahli materi atas materi yang terdapat dalam produk buku panduan sosiodrama ubrug memperoleh total skor sebesar 81\% dengan kriteria sangat layak.

Greene dan Petty (Tarigan dan Tarigan, 2009) menyatakan bahwa buku panduan harus memiliki kualitas yang baik, yaitu dapat menarik minat siswa dalam mempergunakannya, mampu memberikan motivasi kepada pemakainya, memuat konten yang menarik untuk dimanfaatkan oleh siswa, dapat menstimulasi para siswa dalam aktivitas belajar, serta mempunyai konsep yang kuat, tidak samar-samar dan fokus kepada tujuan pembelajaran, dalam penelitian dan pengembangan ini adalah untuk meningkatkan keterampilan komunikasi interpersonal siswa. Pendapat tersebut yang mendasari peneliti menyusun buku panduan pelaksanaan sosiodrama Ubrug dengan penuh kesungguhan sampai dengan selesainya.

Penilaian ahli mengungkapkan buku panduan sosiodrama Ubrug yang disusun peneliti adalah inovasi dalam layanan BK yang sangat menginspirasi, karena selain melatih kemampuan siswa dalam komunikasi interpersonal melalui layanan bimbingan kelompok juga dapat memiliki daya tarik khusus karena penggunaan seni budaya daerah khas Banten, yakni ubrug sebagai media bermain sosiodrama. Selain itu, buku panduan sosiodrama ubrug ini memiliki desain tampilan tiap halaman yang menarik, kombinasi warna-warna yang disesuaikan dengan karakteristik siswa, serta kesesuaian penyusunan konten dalam layout yang memudahkan guru BK maupun siswa dalam penggunaannya, materi-materi yang terdapat dalam buku panduan dibahas dengan menyeluruh dan disesuaikan dengan tujuan serta kompetensi yang harus dicapai yang didasarkan pada kebutuhan siswa, 
adanya tata cara bermain dan ulasan materi pada tiap pertemuannya dapat membangkitkan semangat siswa agar giat dalam mempelajari kembali materi yang sudah diajarkan dan mengajarkan kepada siswa untuk berani mencoba sesuatu hal yang baru, yakni belajar seni budaya daerah ubrug Banten. Hal tersebut apabila dikaitkan dengan pendapat Greene dan Petty (Tarigan, 2009) memperkuat alasan bahwa buku panduan sosiodrama ubrug Banten yang dikembangkan oleh peneliti dinyatakan sangat layak untuk dapat di implementasikan sebagai sumber belajar guru BK dalam layanan bimbingan kelompok di masa mendatang.

Keunggulan lainnya terdapat pada self assessment yang dapat digunakan oleh guru untuk mengukur kemampuan keterampilan komunikasi interpersonal yang dimiliki siswa sebelum dan sesudah melaksanakan bimbingan kelompok dengan penggunaan teknik sosidrama ubrug Banten. Selain itu buku panduan ini juga memberikan pengetahuan tentang seni budaya daerah ubrug Banten, dimana ubrug Banten merupakan seni budaya daerah khas Banten berupa seni drama dengan menonjolkan spontanitas dari para pemainnya dalam menampilkan suatu pertunjukkan yang sarat dengan unsur komedi dan menyelipkan nilai-nilai moral bagi para penontonnya. Adanya penggunaan alat musik daerah memperkuat kekhasan seni ubrug Banten dan keseruan penonton selama menyaksikan pertunjukkan seni ubrug Banten.

Berdasarkan hasil penelitian, pengembangan produk buku panduan pelaksanaan sosiodrama ubrug yang dilakukan oleh peneliti dinilai dapat menunjang kebutuhan siswa dalam rangka melatih dan meningkatkan keterampilan komunikasi interpersonal dan juga memperkenalkan seni budaya daerah Ubrug kepada para siswa sebagai bagian dari upaya pelestarian seni dan budaya daerah Banten, sehingga adanya produk pengembangan buku sosiodrama Ubrug merupakan suatu solusi yang tepat dan layak untuk di implementasikan oleh guru BK di SMP Negeri 11 Kota Serang dalam layanan bimbingan dan konseling.

\section{SIMPULAN}

Penelitian dan pengembangan dengan produk pelaksanaan bimbingan kelompok untuk meningkatkan keterampilan komunikasi interpersonal berupa berupa buku panduan pelaksanaan sosiodrama Ubrug untuk guru BK dan untuk siswa.

Produk buku panduan pelaksanaan sosiodrama Ubrug sudah memenuhi kriteria penilaian uji ahli. Kelayakan tersebut ditinjau kelayakan media mencakup kebahasaan, desain, pewarnaan, grafis, dan tampilan visual, sedangkan ditinjau dari kelayakan materi mencakup aspek kelayakan isi, kelayakan penyajian, kelayakan kebahasaan, kelayakan, kualitas isi dan kemanfaatan dengan fokus meningkatkan keterampilan komunikasi interpersonal siswa melalui penggunaan buku panduan tersebut dalam bimbingan kelompok yang dilakukan oleh BK kepada siswa.

Hasil validasi pada produk buku panduan pelaksanaan sosiodrama Ubrug yang dilakukan ahli media dan ahli materi, diperoleh hasil rata-rata uji ahli media sebesar $85 \%$ dan hasil uji materi sebesar $81 \%$. Maka dapat 
disimpulkan buku panduan pelaksanaan sosiodrama Ubrug yang di susun peneliti dalam kriteria "sangat layak".

\section{DAFTAR RUJUKAN}

Arikunto Suharsimi. 2010. Prosedur Penelitian Suatu Pendekatan Praktek. Jakarta: Rineka Cipta

Branch, R. M. (2009). Instructional Design-The ADDIE Appoarch. New York. Springer

De Vito, J.A. (2013). Komunikasi Antar Manusia. Tangerang. Karisma Publishing Group.

Djannah, W., dan Drajat, (2012). Teknik Sosiodrama Untuk Meningkatkan Kepercayaan Diri Siswa. Tesis. Universitas Sebelas Maret. Surakarta.

Pranoto, W., dan Mahardayani, I.H. (2010). Pelaku Konsumen Remaja Menggunakan Fashion Bermerk ditinjau dari kepercayaan Diri. Jurnal Psikologi Universitas Muria Kudus. Volume 1 Nomor 1.

Putra, Nusa. 2011. Research and development Penelitian dan pengembangan: suatu pengantar. Jakarta: Rajagrafindo Persada.

Roestiyah. 2008. Strategi Belajar Mengajar. Jakarta: Rineka Cipta

Sugiyono. (2017). Metode Penelitian Pendidikan (Pendekatan Kuantitatif, Kualitatif dan Research \& Design. Bandung. Alfabeta.

(2012). Metode Penelitian Pendidikan (Pendekatan Kuantitatif, Kualitatif dan Research \& Design. Bandung. Alfabeta.

Tarigan, HG dan Tarigan, D. (2009). Telaah Buku Teks Bahasa Indonesia. Bandung. Angkasa. 